\title{
Quality of life and Disease activity among Patients with Systemic Lupus Erythematous.
}

\author{
Anaam Mohammed Hassan, Shalaba El-Sayed Abo Zead, Essam Ahamed Mohamed Abda \& Attyiat Hassan \\ Hussein \\ Head Nurse of Infection Control Unit, Assuit University Hospital, Egypt. \\ Professor of Medical Surgical Nursing, Faculty of Nursing, Assuit University, Egypt. \\ Professor of Rheumatology Rehabilitation and Physical Medicine, Faculty of Medicine, Assuit University, Egypt. \\ Lecturer of Adult Nursing, Faculty of Nursing, Assuit University, Egypt.
}

\begin{abstract}
Background: Systemic Lupus Erythematous (SLE) is a prototypical chronic multi organ autoimmune disorder that can lead to significant burden of disease and loss of life expectancy.Aims: to assess quality of life and disease activity of patients with Systemic Lupus Erythematous (SLE) and (SLE) Design: Descriptive research design was utilized in this study. Setting: The study was conducted in Rheumatology and Rehabilitation department at Assiut University Hospital. Sample: A 60 adult patients with (SLE) from both sexes aged among (18-65) years were recruited. Tools: Patient demographic and medical sheet, Systemic Lupus Erythematous disease activity (SLEDAI) scale and Short Form Health Survey 36 (SF-36) scale. Results: The majority of patients (86.7\%) have aged between 18-35 years, females and married. The highest percentage of patients' disease activity were between mild and moderate disease activity with percentage (40.0\% and $30.0 \%$ respectively) As regard quality of life domains (physical functioning, energy/fatigue, pain and general health) of studied group were less than half level of functioning Conclusions: the majority of patients' disease activity were between mild and moderate disease activity with decrease in quality of life Recommendation: Increase SLE patients awareness about the importance of periodic check up to prevent developing any complication related to the disease for enhancing their quality of life.
\end{abstract}

\section{Keywords: Disease activity, Patient's quality of life \& Systemic Lupus Erythematosus (SLE).}

\section{Introduction}

Systemic lupus erythematous (SLE) is the prototypic systemic autoimmune disease characterized by heterogeneous, multisystem involvement and the production of an array of auto antibodies. Clinical features in individual patients can be quite variable, ranging from mild joint and skin involvement to severe, and life-threatening internal organ disease (Daniel \& Bevra, 2013). Prevalence and incidence of SLE vary across gender, geographic regions, and racial/ethnic groups. Prevalence of SLE ranges from 20 to 240 per 100,000 persons, and it's reported incidence rates range from 1 to 10 per 100,000 persons/ years (Pons-Estel et al., 2010). The etiology of SLE includes both genetic and environmental components with female sex strongly influencing pathogenesis. These factors lead to an irreversible break in immunological tolerance manifested by immune responses against endogenous nuclear antigens (Tiffin et al., 2013). Patients with SLE can experience long periods of remission alternating with periods of symptom exacerbation. Almost every organ system can be affected. The most common symptoms, experienced by $95 \%$ of patients at some time during the course of their disease, are fatigue, malaise, fever, anorexia, nausea, and weight loss and musculoskeletal symptoms (Adrianne, 2015)

Many persons with SLE experience high levels of emotional distress. The depression is the most common psychological symptom and the anxiety is another feeling quite frequently experienced. Studies have revealed that the physical symptoms from SLE affect psychologically people who suffer. Skin abnormalities and photosensitivity, disfiguring skin lesions and pleuritic pain are associated with depression, poor self-esteem and poor social functioning. The sufferings from greater organ damage, such as the kidneys, experience greater psychological distress .The disease-related changes to the direct central nervous system can result in depression or anxiety in SLE patients (Zakeri et al., 2011)

The pharmacological treatment is always individual. It depends if it is to control acute, severe flares or to develop maintenance strategies that suppress symptoms and prevent organ damage. This therapy also depends on adverse effects of medications, whether disease manifestations are life-threatening or to cause organ damage, whether manifestations are

Vol , (5) No, (11) August 2017 
potentially reversible and the best approaches to preventing complications of disease (Michalski \& Kodner, 2010)

The most important drugs are: nonsteroidal antiinflammatory drugs, hydroxychloroquine corticosteroids, immunosuppressive drugs (azathioprine, cyclophosphamide, methotrexate, mycophenolate). Almost all patients should take hydroxychloroquine and most corticosteroids with immunosuppressive drugs. With better management, patients with lupus live longer but are at increased risk of disease and treatment-related complications, including infection, cardiovascular disease, and osteoporosis (Taylor \& McMurray, 2011)

The SLE can exert a profound effect on the life of patients, both qualitative and quantitative, with higher mortality rates than the general population. Compared with healthy controls, patients with SLE report lower levels of vitality and general health, with a marked effect of SLE on physical functioning, psychological and emotional status and social life (quality of life) (Schmeding \& Schneider, 2013)

Nursing management focuses on measures to minimize exacerbations and to alleviate symptoms. Administer prescribed medications and monitor for side effects. Before discharge, client education efforts involve reminding the client of the need for close medical follow-up and thorough medication instruction (i.e. never abruptly discontinue taking a prescribed corticosteroid without consulting the physician, and follow the dosage regimen exactly, particularly if the dose is being decreased gradually (Cooper \&, 2014).

\section{Significance of study}

The number of patients with (SLE) admitted at Assiut University Hospital through 2014 are 653 cases and about 394 cases were admitted in Rheumatology and Rehabilitation department according to statistical record.

From the researcher's clinical experience we observed that many patients with SLE go through phases in which they feel that control over their life is slipping from their own hands into those of an unpredictable and unpleasant disease. This sense of powerlessness can occur not only during flares but also during periods of recuperation and remission, patients with (SLE) has physical, emotional and social problem that effect greatly their life. This study will be the first study conducted in this geographical location.

\section{The Aims of the Study}

To assess quality of life and disease activity of patients with Systemic Lupus Erythematous (SLE).

\section{Research question \\ This study is directed to answer the following questions}

- What is the quality of life of patients with Systemic Lupus Erythematous (SLE)?

- What is the disease activity of patients with Systemic Lupus Erythematous (SLE)?

\section{Patients \& Methods}

Research design

Descriptive research design was utilized in this study: Setting

The study was conducted in Rheumatology and Rehabilitation department and outpatient clinics at Assiut University Hospital.

Subjects

A purposive sample of 60 adult SLE patients with (SLE) from both sexes females and males aged between (18-65) years old.

Exclusion criteria:

- Patient aged <18 years old.

- Patient with other autoimmune or infectious disease.

\section{Tools}

Tool 1: Patient demographic and medical data sheet

this tool included two main parts:

First part: demographic data such as: name, age, gender, marital status, occupation and level of education. It included 5 items (question from 1 to 5).

Second part: Medical data of the patient including: duration of disease and family history of disease. It included 2 items (question from 1 to 2 ).

Tool 2: Systemic Lupus Erythematous Disease activity (SLEDAI) Scale

To assess disease activity in individuals with SLE by use of the (SLEDAI) scale. This tool was devolved by Bombardier et al., (1992). It consists of specific manifestation in 9 organs/systems, the number of descriptors $=24$, which divided into 16 descriptors of which are clinical such as seizure, psychosis, organic brain syndrome, visual disturbance, other neurological problems, hair loss, new rash, muscle weakness, arthritis, blood vessel inflammation, mouth sores, chest pain worse with deep breathing and manifestations of pleurisy and/or pericarditis and fever. (8) descriptors of which are laboratory results such as urinalysis testing, blood complement levels, increased anti-DNA (anti-Deoxyribonucleic acid) antibody levels, low platelets and low white blood cell count.

\section{Scoring}

The weighted organ manifestations are summed into a final score, which can range from zero to 105 (Score of first 8 descriptors (each=8), Score of second 6 descriptors (each=4), Score of third 7 descriptors (each=2), Score of fourth 3 descriptors 
$($ each $=1)),($ SLEDAI score $=$ Sum of 24 descriptors $)=$ $(8 \times 8)+(6 \times 4)+(7 \times 2)+(3 \times 1)=105$.

Activity categories have been defined on the basis of SLEDAI scores:

- No activity (SLEDAI = 0)

- Mild activity (SLEDAI = $1-5)$

- Moderate activity (SLEDAI = 6 - 10)

- High activity (SLEDAI = $11-19)$

- Very high activity $=($ SLEDAI $>=20)$

Tool [3]: Short Form Health Survey 36 (SF-36) Scale:

By Ware \& Sherbourne, (1992)

To assess quality of life in individuals with SLE by use of the Short Form Health Survey 36 (SF-36).

\section{Scoring:}

For each of the eight domains that the SF36 measures an aggregate percentage score is produced. The percentage scores range from $0 \%$ (lowest or worst possible level of functioning) to $100 \%$ (highest or best possible level of functioning).

It contains 36 items grouped into eight domains:

- Physical functioning (11 questions).

- Role limitation due to physical health (4 questions).

- Role limitation due to emotional problems (3 questions).

- Energy / fatigue (4 questions).

- Emotional well-being (5 questions).

- Social functioning (2 questions).

- Pain (2 questions).

- General health (5 questions).

Operational Design

This study was conducted through:

Phase I: Preparatory phase

- The study tools were designed after extensive review of literature.

- The content, validity and reliability were done by seven expertise in rheumatology department and medical surgical nursing field.

- 3- Pilot study: were conducted on $10 \%$ of sample in selected setting to evaluate the applicability and clearly of tools, the reliability was tested for the three tools by using Cronback's alpha (tauequivalent reliability) coefficient $\quad(r=0.823$, 0.835 and 0.842 respectively) which its internal consistency "Good", then tools were modified according to the result of pilot study.

\section{Ethical considerations}

- Research proposal was approved from Ethical Committee in the faculty of nursing.

- There is no risk for study subjects during application of research.

- The study followed common ethical principles in clinical research.
- Written consent was obtained from patients or guidance that are willing to participate in study, after explaining the nature and purpose the study.

- Confidentiality and anonymity were assured.

- Study subject have the right to refuse to participate and or withdraw from the study without any rational any time.

- Study subject privacy was considered during collection of data.

\section{Phase II: Administrative phase}

- An official permission was obtained from the head of rheumatology department at Assiut University Hospital.

- Oral permission for voluntary participation was obtained from patients and the nature and purpose of the study will be explained.

- Data was assured for confidentiality.

- Each patient was assessed by using tool I, II and III.

- The data collection was carried out from 23 February to 23 June 2016.

- The researcher introduce himself to initiate line of communication.

- The tools I, II and III were carried out by the researcher during the patients' staying period at hospital.

\section{Statistical design}

The data obtained had reviewed, prepared for computer entry, coded, analyzed and tabulated. Descriptive statistics (frequencies and percentages, mean and standard deviation, i.e.) were done using computer program (SPSS) version (22). Independent sample T-test, Chi-square and One-way-ANOVA tests used in the relationship between patient's quality of life and disease activity. It's considered significant when $\mathrm{P}$. value less than (0.05). 


\section{Results}

Table (1):Frequency and percentage distribution of demographic characteristics \& medical data of the studied patients.

\begin{tabular}{|c|c|c|}
\hline \multirow{2}{*}{ Items } & \multicolumn{2}{|c|}{ Studied patient } \\
\hline & No. $(n=60)$ & $\%$ \\
\hline \multicolumn{3}{|l|}{ Age } \\
\hline $18<35$ & 52 & 86.7 \\
\hline $35-45$ & 8 & 13.3 \\
\hline Range & \multicolumn{2}{|c|}{$20-21$} \\
\hline Mean \pm SD & \multicolumn{2}{|c|}{$29.96 \pm 5.78$} \\
\hline \multicolumn{3}{|l|}{ Gender } \\
\hline Male & 4 & 6.7 \\
\hline Female & 56 & 93.3 \\
\hline \multicolumn{3}{|l|}{ Marital status } \\
\hline Single & 6 & 10.0 \\
\hline Married & 42 & 70.0 \\
\hline Divorced & 8 & 13.3 \\
\hline Widowed & 4 & 6.7 \\
\hline \multicolumn{3}{|l|}{ Level of education } \\
\hline Illiterate & 16 & 26.7 \\
\hline Read and write & 12 & 20.0 \\
\hline Secondary education & 24 & 40.0 \\
\hline High education & 8 & 13.3 \\
\hline \multicolumn{3}{|l|}{ Occupation } \\
\hline Working & 20 & 33.3 \\
\hline Not working & 40 & 66.7 \\
\hline \multicolumn{3}{|l|}{ Duration of illness } \\
\hline Less than 1 year & 32 & 53.3 \\
\hline 1 year to less than 2 years & 16 & 26.7 \\
\hline 2 years to less than 3 years & 8 & 13.3 \\
\hline 3 years to less than 4 years & 4 & 6.7 \\
\hline Range (months - years) & \multicolumn{2}{|c|}{$3-3.6$} \\
\hline Mean \pm SD & \multicolumn{2}{|c|}{$1.4 \pm 0.9$} \\
\hline \multicolumn{3}{|l|}{ Family history with SLE } \\
\hline Yes & 10 & 16.7 \\
\hline No & 50 & 83.3 \\
\hline
\end{tabular}

Table (2): Frequency and percentage distribution of disease activity for patients with Systemic Lupus Erythematous (SLE).

\begin{tabular}{|l|c|c|}
\hline \multirow{2}{*}{\multicolumn{1}{|c|}{ Disease Activity }} & \multicolumn{2}{c|}{ Studied group $(\mathbf{n = 6 0})$} \\
\cline { 2 - 3 } & $\mathbf{N}$ & \% \\
\hline No activity & 6 & 10.0 \\
\hline Mild activity & 24 & 40.0 \\
\hline Moderate activity & 18 & 30.0 \\
\hline High activity & 8 & 13.3 \\
\hline Very high activity & 4 & 6.7 \\
\hline Total & $\mathbf{6 0}$ & $\mathbf{1 0 0 . 0}$ \\
\hline
\end{tabular}




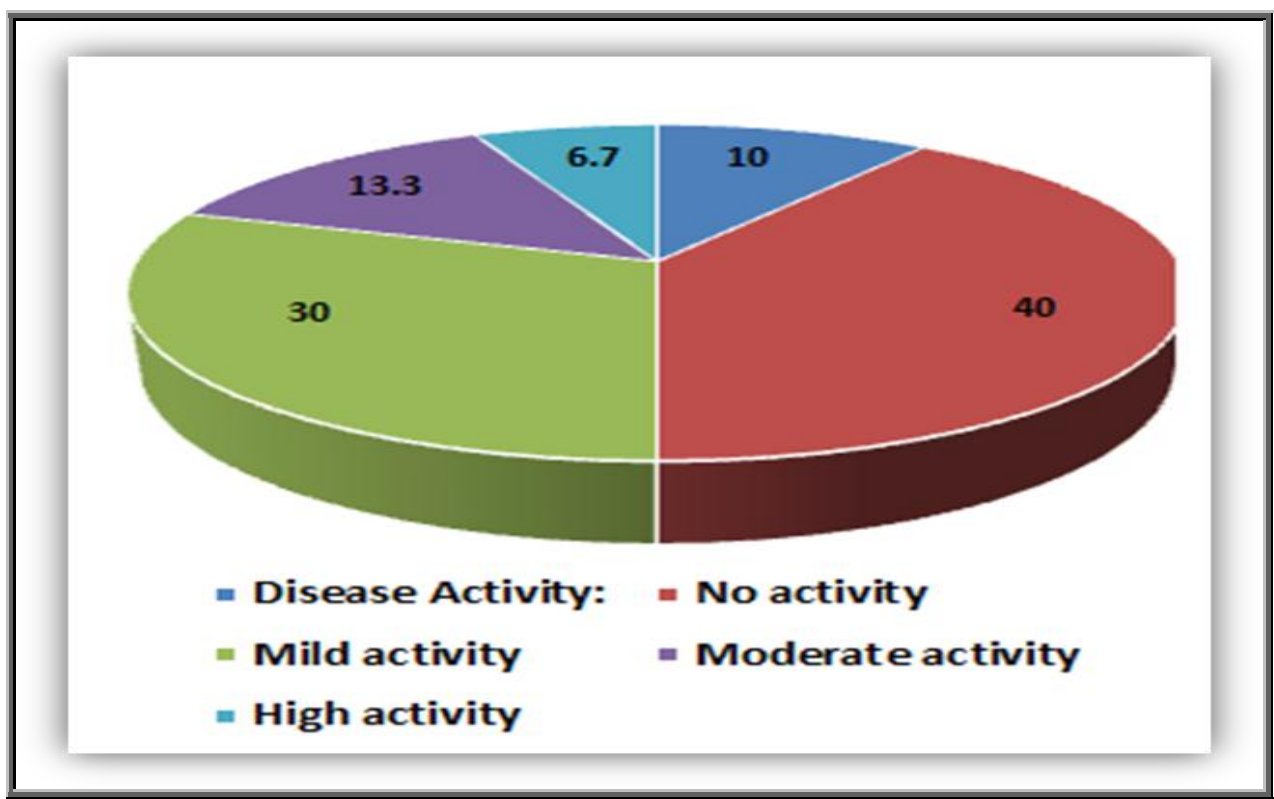

Figure (1): Assessment of patients' disease activity in the studied patients.

Table (3): Quality of life mean scores for patients with Systemic Lupus Erythematous (SLE).

\begin{tabular}{|l|c|}
\hline \multicolumn{1}{|c|}{ Items } & Studied group (n=60) \\
\cline { 2 - 2 } & Mean \pm SD \\
\hline Physical functioning & $37.50 \pm 10.14$ \\
\hline Role limitations due to physical health & $75.00 \pm 43.05$ \\
\hline Role limitations due to emotional problems & $55.55 \pm 49.00$ \\
\hline Energy/ fatigue & $36.66 \pm 7.69$ \\
\hline Emotional well being & $52.93 \pm 7.25$ \\
\hline Social functioning & $51.66 \pm 17.59$ \\
\hline Pain & $31.00 \pm 15.60$ \\
\hline General health & $2.83 \pm 3.63$ \\
\hline Total & $353.21 \pm 142.37$ \\
\hline
\end{tabular}

Table (4): Frequency and percentage distribution of quality of life for patients with Systemic Lupus Erythematous (SLE).

\begin{tabular}{|l|c|c|}
\hline \multirow{2}{*}{\multicolumn{1}{|c|}{ Items }} & \multicolumn{2}{c|}{ Studied group $(\mathbf{n = 6 0})$} \\
\cline { 2 - 3 } & N. & \% \\
\hline Low quality of life & 34 & 56.7 \\
\hline Acceptable quality of life & 26 & 43.3 \\
\hline Total & $\mathbf{6 0}$ & $\mathbf{1 0 0 . 0}$ \\
\hline
\end{tabular}




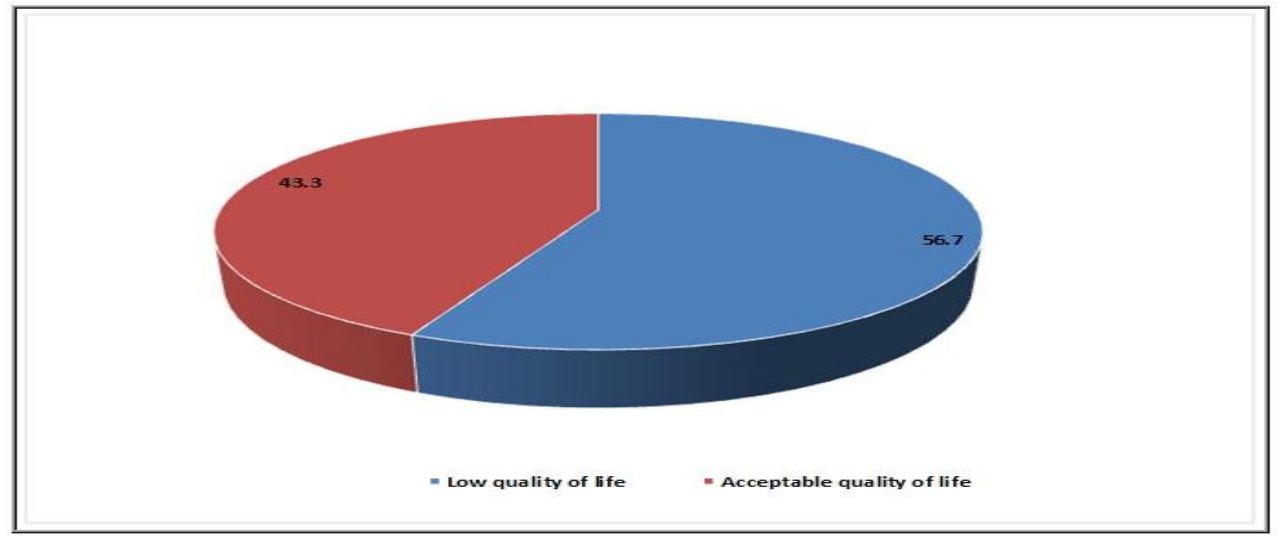

Figure (2): Assessment of patients' quality of life in the studied patients.

Table (5): Relation between patients' disease activity with (demographic characteristics \& medical data).

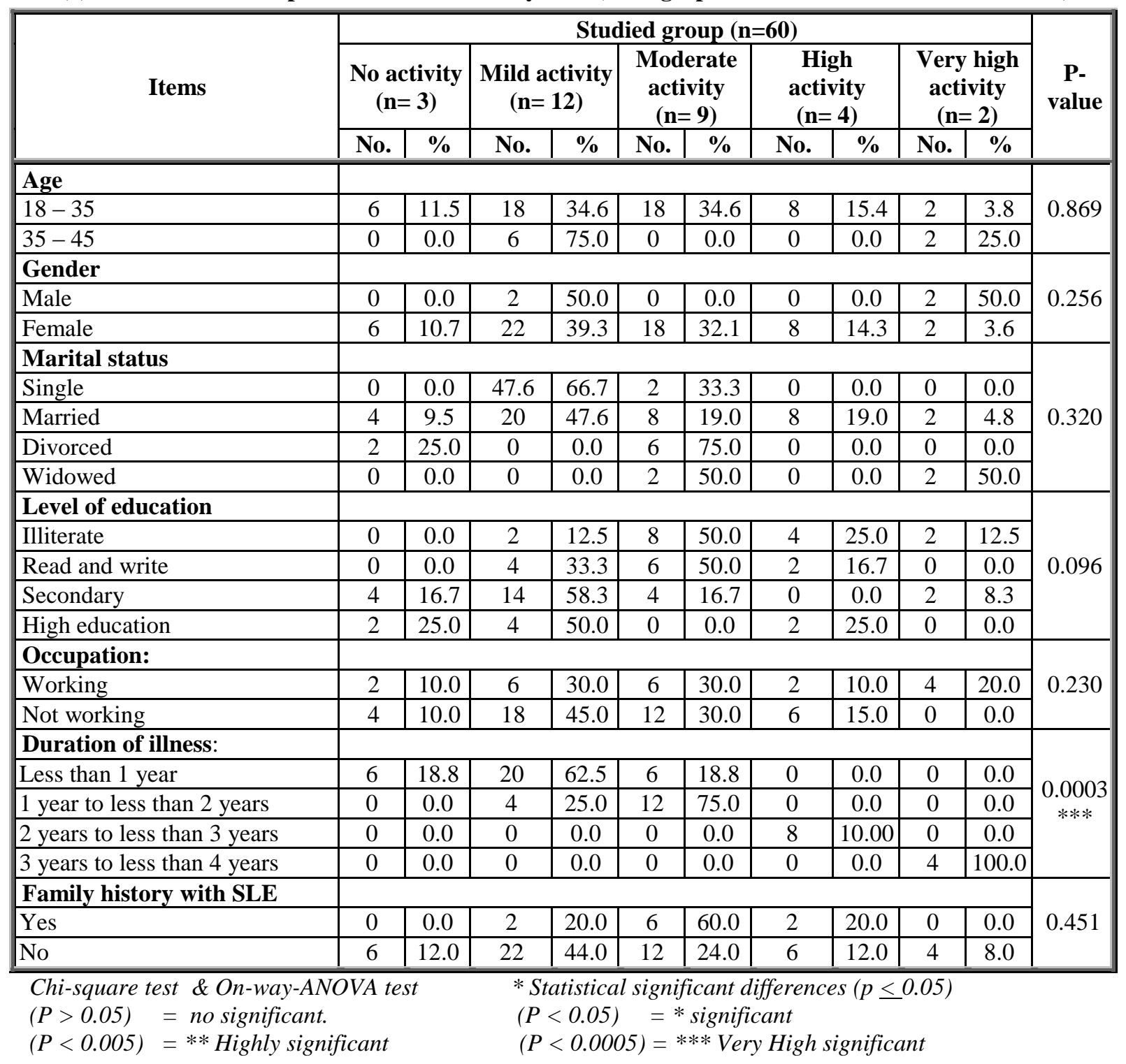


Table (6): Relation between patients' quality of life with (demographic characteristics \& medical data).

\begin{tabular}{|c|c|c|c|c|c|}
\hline \multirow{3}{*}{ Items } & \multicolumn{4}{|c|}{ Studied group $(n=60)$} & \multirow{3}{*}{$\begin{array}{c}\text { P- } \\
\text { value }\end{array}$} \\
\hline & \multicolumn{2}{|c|}{$\begin{array}{c}\text { Low quality of life } \\
(n=34)\end{array}$} & \multicolumn{2}{|c|}{$\begin{array}{l}\text { Acceptable quality of life } \\
(n=26)\end{array}$} & \\
\hline & No. & $\%$ & No. & $\%$ & \\
\hline \multicolumn{5}{|l|}{ Age } & \multirow{3}{*}{0.229} \\
\hline $18-35$ & 28 & 53.8 & 24 & 46.2 & \\
\hline $35-45$ & 6 & 75.0 & 2 & 25.0 & \\
\hline \multicolumn{5}{|l|}{ Gender } & \multirow{3}{*}{0.214} \\
\hline Male & 4 & 100.0 & 0 & 0.0 & \\
\hline Female & 30 & 53.6 & 26 & 46.4 & \\
\hline \multicolumn{5}{|l|}{ Marital status } & \multirow{5}{*}{0.668} \\
\hline Single & 4 & 66.7 & 2 & 33.3 & \\
\hline Married & 24 & 57.1 & 18 & 42.9 & \\
\hline Divorced & 4 & 50.0 & 4 & 50.0 & \\
\hline Widowed & 2 & 50.0 & 2 & 50.0 & \\
\hline \multicolumn{5}{|l|}{ Level of education } & \multirow{5}{*}{0.263} \\
\hline Illiterate & 6 & 37.5 & 10 & 62.5 & \\
\hline Read and write & 6 & 50.0 & 6 & 50.0 & \\
\hline Secondary & 18 & 75.0 & 6 & 25.0 & \\
\hline High education & 4 & 50.0 & 4 & 50.0 & \\
\hline \multicolumn{5}{|l|}{ Occupation: } & \multirow{3}{*}{0.803} \\
\hline Working & 12 & 60.0 & 8 & 40.0 & \\
\hline Not working & 22 & 55.0 & 18 & 45.0 & \\
\hline \multicolumn{5}{|l|}{ Duration of illness } & \multirow{5}{*}{$0.013 *$} \\
\hline Less than 1 year & 18 & 56.2 & 14 & 43.8 & \\
\hline 1 year to less than 2 years & 6 & 37.5 & 10 & 2.5 & \\
\hline 2 years to less than 3 years & 6 & 75.0 & 2 & 25.0 & \\
\hline 3 years to less than 4 years & 4 & 100.0 & 0 & 0.0 & \\
\hline \multicolumn{5}{|l|}{ Family history with SLE } & \multirow{3}{*}{0.428} \\
\hline Yes & 4 & 40.0 & 6 & 60.0 & \\
\hline No & 30 & 60.0 & 10 & 40.0 & \\
\hline
\end{tabular}

Table (7): Pearson correlation coefficients to determine the effect of patients' disease activity \& quality on each other for study group.

\begin{tabular}{|l|l|c|c|}
\hline \multicolumn{2}{|c|}{} & Total Disease Activity & Total Quality of Life \\
\hline \multirow{3}{*}{ Total Disease Activity } & Pearson Correlation & 1.0 & 0.634 \\
\cline { 2 - 4 } & Sig. & - & 0.84 \\
\cline { 2 - 4 } & No. & 60 & 60 \\
\hline \multirow{3}{*}{ Total Quality of Life } & Pearson Correlation & 0.634 & 1.0 \\
\cline { 2 - 4 } & Sig. & 0.84 & - \\
\cline { 2 - 4 } & No. & 60 & 60 \\
\hline
\end{tabular}


Table (1): showed that; the majority of patient have aged between 18-35 years, females, married, educated, and not working with percentages $(86.7 \%$, $93.3 \%$ and $70 \%$ respectively). As regarded medical data, around half of sample had less than 1 year of illness with percentages (53\%) and most of them hadn't a family history with SLE with percentages $(83.3 \%)$

Table (2) \& Figure (1): reflected that; the highest percentage of patients were between mild and moderate disease activity with percentages $(40.0 \%$, $30.0 \%$ respectively).

Table (3): reflected that, the (physical functioning, energy/fatigue, pain and general health) of studied group was less than $50 \%$ for level of functioning with Mean \pm SD $\quad(37.50 \pm 10.14, \quad 36.66 \pm 7.69,31.00 \pm 15.60$ and 2.83 \pm 3.63 respectively). As regard (Role limitations due to physical health, Emotional wellbeing and social functioning) of studied group was nearly equal to $50 \%$ for level of functioning with Mean \pm SD $\quad(55.55 \pm 49.00, \quad 52.93 \pm 7.25$ and $51.66 \pm 17.59$ respectively)

Table (4) \& Figure (2): reflected that, above half of patient had Low quality of life with percentage $(56.7 \%)$

Table (5): showed that, there is very highly statistical difference between patients' disease activity and duration of illness with p- value $(0.0003 * * *)$.

Table (6): showed that, there is statistical difference between patients' quality of life and duration of illness with p- value $\left(0.013^{*}\right)$

Table (7): reflected that, there were correlation between patient's quality of life and disease activity with Pearson correlation $=0.634$.

\section{Discussion}

Health outcomes and their measures used as end points in (SLE). Patient care and clinical trials have been varied and are still evolving. Although significant reductions in morbidity and mortality in SLE have been achieved, the medications approved for SLE have remained the same during the past 50 years (Jolly et al., 2010)

The Discussion covered the main results finding as follow

\section{Demographic characteristics of patients SLE}

The (SLE) is a heterogeneous disease, and its phenotype and outcomes vary widely. Ethnic and geographical variations are well documented factors associated with its heterogeneity (Sanchez et al., 2011)

Based on the results of the present study, the highest percentage of patients were between the ages 18-35 years old, females. (Guillermo et al., 2010) in the same line with the current study finding, show that an increased risk of SLE among reproductive age women.

This finding is supported by Hussaini et al., (2014) who represented that SLE is a chronic autoimmune disorder, the exact etiology of which is unknown. SLE predominately affects younger women; however, it is reported to occur in up to $20 \%$ of patients 50 years or older. In patients with SLE, nearly every system in the body is affected with varying degrees of severity ranging from sub clinical to fatal.

Lim et al., (2014) mentioned that the females predominance in SLE may indicate that hormonal influences play a part, but the precise role of estrogens is unclear, In this aspect Louise et al., (2016) in the same line with the current study which revealed that higher incidence rates among women than among men, particularly in younger persons.

II- Patient's disease activity about SLE

In the evaluation of patients with SLE it is important to measure not only disease activity (which is potentially reversible with treatment) and damage (which is permanent and can be due to the disease or treatment) but also the patients' perspective. This is because the disease is likely to have a significant impact on the physical, social and psychological aspects of the patient health and QoL.

Systemic lupus erythematosus disease activity (SLEDAI) is widely accepted as a tool for monitoring SLE activity both in clinical practice and in research (Mina et al., 2012).

The current study revealed that the highest percentage of patients having mild and moderate disease activity.

This is in line with (Wayne, 2015) who stated that despite treatment, a significant percentage of patients with (SLE) have moderate to severe disease activity.

Similarly, another study conform that above half of the SLE population in the study had mild activity and nearly quarter had moderate to severe activity. No activity was present in $13 \%$, while $16 \%$ had from moderate to severe activity (Hamdy et al., 2010).

In one study done by Muñoz et al., (2016) who found that in newly diagnosed SLE patients, male gender is associated with higher disease activity despite the fact that male and female patients seem to experience similar overall disease manifestations.

III- Patient's quality of life about SLE

The current study which revealed that the (physical functioning, energy/fatigue, pain and general health) of studied group was less than half for level of functioning. As regard (Role limitations due to physical health, Emotional wellbeing and social functioning) of studied group was nearly equal to half for level of functioning. 
In this aspect Hamdy et al., (2010) reported that all domains of SF-36 including general health, physical functions, physical limitations, energy/fatigue, emotional well-being, pain, social functions, and health changes were significantly lower in SLE patients compared to controls.

Jolly et al., (2010) in the same line with the current study which observed a progressive decrease in all SF-36 scores. These progressive changes could be due to several factors, such as SLE progression along the years, continuously coping with a chronic illness, and practical management items that may be required (frequent medical visits, laboratory examinations, etc.)

Finally, it's important for people with SLE to receive regular health care, instead of seeking help only when symptoms worsen. Results from a medical exam and laboratory work on a regular basis allow the doctor to note any changes and to identify and treat flares early. The treatment plan, which is tailored to the individual's specific needs and circumstances, can be adjusted accordingly. If new symptoms are identified early, treatments may be more effective.

\section{Conclusion}

The majority of patient have aged between 18-35 years, females, married, educated, and not working. The highest percentage of patients' disease activity were having mild and moderate disease activity. The quality of life domains (physical functioning, energy/fatigue, pain and general health) of the studied group was less than half for level of functioning

\section{Recommendation}

- Increase SLE patients awareness about the importance of periodic check up to prevent developing any complication which can affect quality of life.

- The nurse should give SLE patients and their family member's adequate verbal and written information about their medication regimen, how to take their medication and their side effect.

- Establishment of continuous health education program for patient with SLE at rheumatology department, to provide health teaching using booklet and illustrated

- Reapply this research on a larger probability sample acquired from different geographical areas in Egypt for generalization.

\section{References}

1. Adrianne D., (2015): Introduction to MedicalSurgical Nursing, $6^{\text {th }}$ Edition, Chapter (34) Immune disorder, Canada, PP: 658.
2. Bombardier C., Gladman D., Urowitz M., Caron D., \& Chang C., (1992): Derivation of the SLEDAI. A disease activity index for lupus patients. The Committee on Prognosis Studies in SLE. Arthritis Rheum J, Volume 35, PP: 630-40.

3. Cooper \& Kelly G., (2014): Foundations and Adult Health Nursing, Unit VI Adult health nursing, 7 edition, Canada, PP: 1312.

4. Daniel J., \& Bevra H., (2013): Dubois1 Lupus Erythematosus and Related Syndromes, section 1, 8 edition, China, PP: $1-5$.

5. Guillermo J., Pons-Estel., Graciela S., Alarcón \& Lacie Scofield, (2010): Understanding the Epidemiology and Progression of Systemic Lupus Erythematosus, Arthritis \& Rheumatism, Volume 39, Issue 4, PP: 257-268.

6. Hamdy S., Gamal T., Khalil A., \& Nagwa I., (2010): Pattern of systemic lupus erythematosus in Egyptian patients: the impact of disease activity on the quality of life, Volume 6, Issue 14, PP: 233-239.

7. Hussaini M., Hammouda E., \& Hammouda A., (2014): Optimizing pharmacotherapy of systemic lupus erythematosus: the pharmacist role. International Journal of Clinical Pharmacy, Volume 36, issue 4, PP: 684-92.

8. Jolly M., Pickard A., Wilke C., Mikolaitis R., Teh L., McElhone K., Fogg L., \& Block J., Ann, (2010): Lupus-specific health outcome measure for US patients Rheum Dis, Volume 69, Issue 1, PP: 29-33.

9. Lim S., Bayakly A., Helmick C., \& et al., (2014): The incidence and prevalence of systemic lupus erythematosus, the Georgia Lupus Registry. Arthritis Rheumatol J, Volume 66, PP: 357-368.

10. Louise F., Hermansen J., Christian T., Mikkel F., \& Søren J., (2016): Incidence of Systemic Lupus Erythematosus and Lupus Nephritis in Denmark: A Nationwide Cohort Study, Rheum J, Volume 34, Issue 7, PP: 1335-9.

11. Michalski J., \& Kodner C., (2010): Systemic lupus erythematosus: safe and effective Management in primary care. Rim Care. Volume 37, Issue 4, PP: 767-78.

12. Mina R., Klein-Gitelman M., Ravelli M., Beresford M., Avcin T., Espada G., \& et al., (2012): Inactive disease and remission in childhood-onset systemic lupus erythematosus. Arthritis Care Res (Hoboken) J, Volume 64, Issue 5, PP: 683-93.

13. Muñoz-Grajales C., González L., Alarcón G., \& Acosta-Reyes J., (2016): Gender differences in disease activity and clinical features in newly diagnosed systemic lupus erythematosus, Lupus J, Volume 25, Issue 11, PP:1217-23. 
14. Pons-Estel G., Alarcon G., \& Scofield L., (2010): Understanding the epidemiology and progression of Systemic lupus erythematous, Semin Arthritis Rheum J, Volume 39, PP: $257-$ 268.

15. Sanchez E., Nadig A., \& Richardson B., (2011): Phenotypic associations of gentic susceptibility loci in systemic lupus erythematosus, Ann Rheum, Volume 70, Issue 10, PP:1752-7.

16. Schmeding A., \& Schneider M., (2013): Fatigue, health-related quality of life and other patient-reported outcomes in systemic lupus erythematosus. Best Practice and Research. Clinical Rheumatology J, Volume 27, Issue 3, PP: 363-375

17. Taylor J., \& McMurray R., (2011): Medical therapy for systemic lupus erythematosus. Miss State Med Assoc. J, Volume 52, Issue 2, PP: $39-$ 43.

18. Tiffin N., Adeyemo A., \& Okpechi I., (2013): A diverse array of genetic factors contributes to the pathogenesis of systemic lupus erythematosus. Orphanet Journal of rare disease, Volume 8, Issue 2, PP: 1186-1750

19. Ware J., \& Sherbourne C., (1992): The MOS 36-Item Short-Form Health Survey (SF-36): Conceptual Framework and Item Selection, Medical Care, Volume 30, PP: 473 48.

20. Wayne K., (2015): Disease Activity in SLE Is Common despite Treatment, Lupus J., Volume 24, Issue7, PP: 633-653.

21. Zakeri Z., Shakiba M., Narouie B., Mladkova N., Ghasemi-Rad M., \& Khosravi A., (2011): Prevalence of depression and depressive symptoms in patients with systemic lupus erythematosus: Iranian experience. Rheumatol Int J. Volume 32, Issue 5, PP: 1179-87. 